\title{
El Trabajo Social ante la crisis. Nuevos retos para el ejercicio profesional de los y las trabajadoras sociales
}

\author{
Social Work in the face of the crisis: new challenges in professional \\ practice for social workers \\ Begoña ABAD MiguÉLEZ \\ Universidad del País Vasco (España) \\ begona.abad@ehu.eus \\ Idoia MARTÍN ARANAGA \\ Universidad del País Vasco (España) \\ idoia.martin@ehu.eus
}

Recibido: 04/04/2015

Revisado: 15/04/2015

Aceptado: 28/07/2015

Disponible on line: $25 / 11 / 2015$

\section{Resumen}

El impacto de la reciente crisis en la vida de ciudadanos y ciudadanas es innegable, a tenor de los datos disponibles: se dispara el número de parados y paradas, aumenta la tasa de pobreza y, con ello, el número de potenciales beneficiarios y beneficiarias de los sistemas de protección social. Sin embargo y al mismo tiempo, el Estado de bienestar se tambalea bajo políticas de contención del déficit que redundan en recortes en los servicios públicos de protección y atención social. ¿Cómo se abordan los problemas sociales y en particular la atención social en este contexto? ¿En qué medida la aparición de lo que ha denominado la «nueva cuestión social» y el declive del Estado de bienestar pueden asociarse a los cambios en la forma de entender y ejercer la profesión y en concreto, a los retos que debe afrontar el trabajador o la trabajadora social? Responder a estas preguntas nos lleva a plantear un cambio de paradigma que se traduce en la constante auto-conceptualización profesional y la adecuación situacional del trabajador o la trabajadora social en el ejercicio de sus funciones. Este ejercicio de reflexividad implica la puesta en juego de distintas lógicas de acción que dan lugar a otras tantas figuras profesionales del trabajo social.

Palabras clave: Trabajo Social, crisis, precarización, lógicas de acción, auto-conceptualización profesional.

\begin{abstract}
In the light of the available data, the recent crisis has had an undeniable impact on the life of citizens: the unemployment rate has rocketed and the poverty rate has increased, resulting in a larger number of potential beneficiaries in the social protection systems. However, and at the same time, the welfare state is tottering under deficit reduction policies that have led to public services cuts related to social protection and care. How are social problems, and particularly social care, tackled in this context? To what extent can the appearance of the so-called «new social question» and the decline of the welfare state be linked to changes in the understanding and practice of the profession and, specifically, the challenges social workers must face? Responding to these questions causes us to suggest a paradigm shift resulting in constant professional self-conceptualization and the situational adaptation of social workers when performing their duties. This reflective exercise involves the implementation of different logical lines of action that lead to other professional figures in social work.
\end{abstract}

Keywords: Social Work, crisis, precarization, lines of action, professional self-conceptualization.

Referencia normalizada: Abad Miguélez, B. y Martín Aranaga, I. (2015): «El Trabajo Social ante la crisis. Nuevos retos para el ejercicio profesional de los y las trabajadoras sociales». Cuadernos de Trabajo Social, 28(2): 175-185.

Sumario: 1. Retrato de la crisis. 2. Precariedad como condición. 3. De la precariedad a la precarización como forma de gobernanza. 4. Trabajo Social en el contexto de crisis. 5. Hacia una tipología de figuras profesionales del Trabajo Social. 6. Referencias bibliográficas. 


\section{Retrato de la crisis}

Los discursos técnicos sobre la crisis - y gran parte de los académicos - han tendido a enfocar sus respectivos análisis en la esfera de lo económico aportando cifras e indicadores macroeconómicos: evolución del Producto Interior Bruto (PIB) y de la actividad económica, evolución de las inversiones y el consumo, evolución de los niveles de déficit y gasto, etc.

Pero lo cierto es que, lejos de encontrarnos ante un episodio más del ciclo económico de la economía capitalista, nos encontramos ante una crisis de lo social (Zurdo Alaguero y Serrano Pascual, 2013) porque, más allá de su impacto en la esfera económica y/o financiera, sus consecuencias se extienden al conjunto del espacio social afectando a las condiciones de vida y a las relaciones de ciudadanos y ciudadanas, con el consiguiente efecto de incremento del riesgo de vulnerabilidad social y quiebra de la cohesión social.

Los datos de los que disponemos dibujan un retrato sombrío de la situación social. Con la crisis, en el período comprendido entre 2008 y 2012, ha empeorado el reparto de la renta y la riqueza produciéndose un proceso de empobrecimiento notable. Los ingresos medios por hogar han ido descendiendo (de 30.045 euros en 2008 a 26.775 euros en 2012) (INE, 2014). El umbral de riesgo de pobreza ${ }^{1}$ era, en 2009 , de 7.980 euros por persona adulta descendiendo a $7.355 \mathrm{eu}-$ ros en 2012. La tasa de pobreza ${ }^{2}$ ha pasado del 19,7 al 21,1 por ciento, mientras la pobreza severa alcanza ya a 3.000 .000 de personas (Caritas, 2013, p. 7). La distribución de esta tasa muestra diferencias significativas por grupos socio-demográficos afectando, especialmente, a los grupos más vulnerables (personas mayores, menores, mujeres, inmigrantes $)^{3}$. El endeudamiento observado durante el ciclo económico expansivo no se ha reducido durante los años de crisis, gravando, especialmente, a los sectores con menores ingresos (en 2008 la deuda pendiente de los hogares pobres suponía una carga 17 veces mayor en relación a su patrimonio que en el caso de los hogares con mayor riqueza) (Colectivo IOE, 2013, p. 15). En este proceso destaca el endeudamiento hipotecario. Según los datos disponibles, más de 300.000 familias afectadas por la crisis y el desempleo no han podido hacer frente a sus deudas hipotecarias. Si a esta cifra añadimos la de quienes no pueden hacer frente a un alquiler, entre 60.000 y 70.000 cada año en el ciclo de crisis, el resultado es más de medio millón de familias desalojadas de sus viviendas (Colectivo IOE, 2013, p. 16).

Todos estos indicadores nos muestran el impacto social de una crisis que está afectando las condiciones de vida de ciudadanos y ciudadanas, sobre todo, las de quienes se encuentran en paro y no reciben ninguna prestación de desempleo. Según la Encuesta de Condiciones de Vida (INE, 2014), el 16,9 por ciento de los hogares españoles manifiesta llegar a fin de mes con «mucha dificultad»; este porcentaje supera en 3.4 puntos al registrado en 2012. Igualmente, el 41,0 por ciento de los hogares no puede afrontar gastos imprevistos, y el 9,3 por ciento tiene retrasos en los pagos relacionados con la vivienda habitual (hipoteca o alquiler, recibos de gas, electricidad, comunidad, etc.).

Por su parte, la política social desarrollada en estos años de crisis ha estado marcada por el ajuste presupuestario. Los recortes en ámbitos como la sanidad, la educación, los Servicios Sociales y la dependencia han contribuido a deteriorar aún más las condiciones de vida. Como señala Cáritas (p. 18), los recortes en sanidad están provocando un aumento de gasto en medicamentos, situaciones de desatención sanitaria, abandono de tratamientos, etc. Los recortes en educación, por su parte, generan situaciones como acceso restringido a becas, falta de atención a necesidades educativas especiales y situaciones de desigualdad por falta de recursos para adquirir material escolar básico o acceder a activida-

${ }^{1}$ El umbral de riesgo de pobreza se fija en el 60 por ciento de la mediana de los ingresos por unidad de consumo de las personas. Por tanto, aumenta o disminuye en la medida en que lo haga la mediana de los ingresos. Al disminuir los ingresos de la población también disminuye el umbral de riesgo de pobreza (INE, 2014).

${ }^{2}$ La tasa de riesgo de pobreza es el porcentaje de personas cuyos ingresos en el año anterior están por debajo del umbral de pobreza (INE, 2014).

3 Así, «mientras disminuye la tasa entre los mayores de 65 años (de 2.1 puntos entre 2012 y 2013), entre los menores de 16 años se situó en el 26,7 por ciento siendo 6.3 puntos superior a la del conjunto de la población» (INE, 2014, p. 2). 
des extraescolares. Los recortes en dependencia están provocando pérdida de ayudas económicas para cuidados familiares, aumento del número de personas dependientes sin cobertura y retrasos en las concesiones (p. 19). Por último, en el ámbito de los Servicios Sociales los recortes provocan desprotección social, retrasos y endurecimiento del acceso (lo que provoca sobrecarga en la familia y aparición de estrategias de supervivencia relacionadas con la economía sumergida y/o la mendicidad), reducción de la calidad de los servicios (al dar prioridad a la tramitación y a lo urgente) cuando no derivación a otras entidades como Cáritas (el 67 por ciento de las personas que acuden a esta organización ha pasado antes por los servicios públicos) (p. 19). La evolución de personas atendidas en Cáritas, en el período de crisis, ha pasado de 370.251 en 2007 a 1.300 .914 personas en 2012. Entre ellos, el 26 por ciento son personas solas, mientras que el 74 por ciento son familias (p. 24).

El proceso de endeudamiento y empobrecimiento, junto con la política de recortes, ha provocado que un número creciente de personas que no pueden cubrir sus necesidades básicas (alimentación, vivienda, ropa, etc.) por sus propios medios, o a través del modelo de bienestar vigente, acudan a entidades sociales de carácter privado en busca de ayuda. Este es el rostro que se dibuja en el retrato de una crisis que, como efecto, fractura la estructura social, pone en riesgo la cohesión social, pero, sobre todo, nos presenta los contornos de «un nuevo modelo de sociedad que pasa del pacto social al contrato mercantil, de la solidaridad colectiva al individualismo meritocrático, cambiando la estructura del bienestar fundado en derechos» (p. 5) para instaurarse en la precariedad como gramática social.

\section{Precariedad como condición}

Atendiendo a los datos, podemos concluir que la crisis económica y financiera han incrementado tanto las condiciones como el número de personas en situación de precariedad. Y el fenómeno es un proceso global (Sassen, 2010), lo que explica el creciente interés, que ha cobrado en el mundo académico, la noción de precariedad, o mejor aún, la política de la precariedad (politics of precarity).

Ahora bien, ¿qué entendemos por precariedad? Siguiendo a Butler (2009) podemos distin- guir dos dimensiones básicas en la noción de precariedad: la precariedad como realidad socioontológica (precariousness) y la precariedad como efecto de medidas políticas, sociales y legales adoptadas con el fin de afrontar la precariedad ontológico-social (precarity).

El término precariedad remite, en una primera acepción, a «la condición de ser o estar condicionado», condición que «descansa sobre una concepción de la persona como fundamentalmente dependiente de, y condicionada por, un mundo sostenido y sostenible» (p. 34). En este sentido, denota la condición relacional de la existencia: el ser humano nace con sentimiento de precariedad, de vulnerabilidad, de modo que necesita un entorno social y cultural fuerte, de interrelación con otros seres también precarios, y un largo proceso de socialización para gestionar esa precariedad ontológica. Estamos, entonces, ante un principio ontológico común, compartido con otros que, a la vez, son fuente de amenaza y de solución en la medida en que sólo con otros podemos solventar la condición inicial.

La segunda dimensión, en su consideración de efecto, apunta a un proceso de categorización, de jerarquización frente a la precariedad asociado a relaciones de dominación y de control de la definición de la realidad. El carácter social de la precariedad ontológica remite a las condiciones políticas y las prácticas sociales que la comunidad pone en marcha para gestionar la precariedad y la interrelación entre seres precarios. Estas decisiones sociales y políticas establecen fronteras, jerarquías entre quienes deben ser protegidos $-\mathrm{y}$ hasta dónde - y quiénes no, por ser fuente de inseguridad y amenaza (los otros, los extraños, etc.).

Butler denomina precarity a esta distribución diferencial de las inseguridades simbólicas y materiales que, derivada de la concepción hobbesiana de la precariedad como amenaza, determina formas de dominación y jerarquización y, en última instancia, convierte en desigualdad un principio ontológico común. En este sentido podemos entender que:

La clasificación de la similitud socio-ontológica produce desigualdad. La precariedad [precarity] puede entonces entenderse como un efecto funcional que emerge de regulaciones legales y políticas presumiblemente destinadas a proteger de una precariedad [precariousness] general, existencial. Desde esta perspectiva, la dominación 
implica el intento de salvaguardar a algunos de la precariedad existencial mientras, al mismo tiempo, la protección privilegiada se basa en una distribución diferencial de la precariedad [precarity] de todos aquellos que son diferentes y considerados menos merecedores de protección (Lorey, 2011, p. 4$)^{4}$.

Así entendida, la precariedad - y sus sinónimos vulnerabilidad y exclusión (Castel, 1999) deviene una experiencia conectada con regímenes de valor y capacitación diferenciales a lo largo de variables socioeconómicas y culturales diversas: género, etnia, posición en el mercado laboral, etc. En este sentido, remite a relaciones de poder concretas que hacen al sujeto precario en varios sentidos, desde en sus capacidades para la reproducción material, hasta en su propia subjetivación, pasando por el lugar que ocupa en la formación social.

La precariedad se asocia, así, a unas relaciones de poder que producen condiciones estructurales (sociales, económicas, políticas) en las que las capacidades del sujeto, o de algunos sujetos, se ven minadas por una incertidumbre generalizada como principio de existencia que dificulta o imposibilita las conexiones entre decisiones, acciones y resultados. Esto se traduce en dificultades para la acción, para la agencia en términos temporales (horizonte temporal incierto: dificultad para generar planes y proyectos de vida, etc.) y espaciales (horizonte espacial incierto: desahucios, deportación, expulsión, migración, etc.).

La incertidumbre, en tanto que característica de la precariedad, supone una clara limitación de la capacidad de agencia para el sujeto en tanto en cuanto se rompen las conexiones entre decisiónacción-resultados. La certeza parece ser el único modo de lograr una vinculación significativa entre ellos. Pero certeza significa acciones y resultados fijados previamente por el marco de poder institucional en el que se inscribe el sujeto. Dicho de otro modo, la certeza expresa una condición en la cual tanto el horizonte temporal como especial de la agencia están previamente delimitados por entramados de poder e institucionales fuertes respecto a los que el sujeto se sitúa en relación de dependencia. En este sentido coincidimos con Beck (1998) en que mayores niveles de individualización no siempre se traducen en ma- yores niveles de agencia, sino en mayores niveles de control y dependencia institucional. Y a mayor dependencia institucional, mayor vulnerabilidad y mayor interiorización de la precariedad como condición ontológica, como forma de subjetivación que puede consolidar una forma de gobernanza basada en la precarización.

\section{De la precariedad a la precarización como forma de gobernanza}

En el contexto de la modernidad clásica la precariedad es concebida como efecto de la propia vida social, del miedo de todos respecto a todos. Con el fin de gestionar esta experiencia de precariedad surge un imaginario social - progreso, razón, ciencia, etc. - que, encarnado en instituciones fuertes, dibuja un horizonte de seguridad, de protección ante la vulnerabilidad, el riesgo y la precariedad. Este imaginario consigue exorcizar el demonio de la precarización haciendo que los riesgos - enfermedad, desempleo, exclusión social, etc. - se vuelvan calculables para la mayoría de la población de modo que la precariedad pasa a ocupar posiciones residuales, atípicas, periféricas.

En el momento actual asistimos a la disolución de este imaginario bajo la normalización de la precariedad. La precariedad, inseguridad, vulnerabilidad dejan de ser fenómenos marginales para normalizarse hasta ocupar el centro de la definición social. En el actual contexto de crisis, pero sobre todo en el marco de las políticas neoliberales vigentes, la gestión de la precariedad ontológica adquiere un matiz propio que podemos denominar «política de precarización». Esta nueva forma de regulación social incluye, al menos, dos dimensiones: por un lado, una forma de gobernanza basada en políticas y medidas destinadas a consolidar la incertidumbre como condición/experiencia normalizada ${ }^{5}, \mathrm{y}$, por otro, un modo de control y regulación basado en la interiorización de la incertidumbre como principio de definición subjetiva, como principio de subjetivación.

El resultado de ambos procesos es la emergencia de una nueva gramática social configurada en torno a la violencia estructural que sistemáticamente padece la población. Nos interesa detenernos ahora en la descripción de dos de los

\footnotetext{
4 Traducción de las autoras.

5 En esta línea, recortes, relaciones laborales precarias, disminución y/o pérdida de derechos sociales, etc.
} 
pilares que sustentan esta gramática social: la privatización de lo social y la psicologización de la vulnerabilidad/incertidumbre/precariedad.

El primero alude a un proceso de privatización de los derechos, es decir, al proceso en virtud del cual el traspaso del poder de determinar su contenido acaba recayendo en manos privadas de modo tal que lo que, en el contexto del Estado de bienestar y la bonanza económica, era exigible al Estado (derecho a la salud, a la educación, a la jubilación, entre otros), pasa a ser considerado un producto que, gestionado por empresas privadas, sólo podrá ser adquirido por quienes tengan capital para ello.

Esta privatización de derechos tiene una doble dimensión. Por un lado, asistimos a cierta mercantilización de la asistencia perceptible en la externalización de servicios a empresas privadas y en la proliferación de relaciones de clientelismo en torno «a grandes estructuras que captan cuantiosos recursos, recurriendo incluso a técnicas propagandísticas y de marketing》 (Barrera, Malagón y Sarasola, 2013, p. 120). Por otro lado, asistimos a un cambio en la concepción de la solidaridad y la atención social. Esta resignificación implica que «es la Sociedad - no el Estado - la que tiene que procurarse su propio bienestar» (pp. 119-120). De este modo, las respuestas a la cuestión social, a los problemas sociales, ya no dependen de la intervención activa del Estado sino de ciudadanos/as o grupos de ciudadanos/as con capacidad para organizarse y gestionarlas, de modo tal que el término Estado (particularmente Estado del bienestar) deja su lugar al término Sociedad (particularmente Sociedad del bienestar) y las políticas sociales «devuelven la atención social de las personas y grupos que necesitan de ayuda hacia las familias, los vecinos, las asociaciones voluntarias, etc.» (p. 120) En este proceso no sólo se transfieren responsabilidades y obligaciones, sino que la propia idea de atención social se reformula pasando de ser concebida como deber de justicia a ser entendida y ejercida como deber moral. Algunos denominan refilantropización (Netto, 2002) o neofilantropía (Aquin, 2001) a esta nueva definición. En cualquier caso, esta reformulación, como veremos más adelante, exige una reflexión y posicionamiento por parte del o la trabajadora social.

El segundo es la consecuencia esperada de una desocialización y despolitización crecientes de la problemática social, o mejor aún, de la interpretación de la cuestión social en clave de un individualismo creciente sobre el que ya nos advertía Beck (1998) al sostener la tesis sobre el desarrollo de un potente proceso de individualización que conduce a la búsqueda de soluciones biográficas para problemas sistémicos.

La individualización en la gestión del riesgo (incertidumbre, precariedad) implica modalidades y referentes de construcción de individualidad que ensalzan, reforzados por discursos institucionales, el esfuerzo y las capacidades individuales en la resolución de los problemas cotidianos. Nos encontramos, pues, ante un traspaso de la responsabilidad de la gestión de las condiciones de precariedad a los propios individuos quienes, de este modo, asumen dichas condiciones como parte de la experiencia. Este discurso pretende generar individuos autónomos, capaces de elaborar su propio proyecto personal y de responsabilizarse del devenir del mismo, esto es, sujetos emprendedores de sí mismos que asumen éxitos y fracasos en términos individuales y psicológicos pues el fracaso en la gestión del proyecto se interioriza como auto culpabilización. Sobre este sentimiento de responsabilidad y autoculpabilidad acaba, en última instancia, sustentándose la definición social como sujetos carentes, sujetos por defecto, a los que de alguna manera hay que tutelar mediante prácticas filantrópicas, caritativas, paternalistas, alejadas del principio de justicia y cargadas de un alto componente de control y vigilancia: infinidad de formularios que rellenar, certificaciones que presentar, trámites que realizar para poder justificar la petición y, en último término, recibir la ayuda.

La dimensión de control y vigilancia nos habla de un individualismo negativo, desocializante (Castel, 1999), que constriñe los límites de la individualización a los contornos de la definición institucional produciendo, desde el punto de vista de los sujetos, un efecto paradójico: el mandato de mayor autonomía y responsabilización se traduce en mayor dependencia institucional en tanto en cuanto el reconocimiento social de la precariedad pasa necesariamente por el reconocimiento institucional. Esto modifica sustancialmente la visión del papel institucional, del funcionamiento práctico de la propia institución y de la relación sujeto-institución. En el primer sentido, Soulet (2005) señala que, en este esquema, las instituciones «no se distinguen tanto por 
una función instituyente, que asigna conductas e impone desde el exterior normas y comportamientos de acción, sino que juegan un rol de continente, que los individuos llenan significativa y normativamente, y ello por el hecho mismo de que persiguen la búsqueda de su propia realización» (p. 98). Internamente, esto se traduce en el desarrollo de políticas individualizadas de asistencia y acompañamiento caso por caso que, ante la exigencia de mayor eficacia y productividad, en la práctica se traducen en mayor burocratización y rutinización de una tarea centrada en certificar la correcta aplicación de recursos escasos. Pero aún más, y abundando en la idea de dependencia institucional y de control, el trabajo institucional de reconocimiento se convierte en una suerte de magistratura moral (magistrature moral) que evalúa, reconoce o desestima. En este sentido, Castel, al referirse a la renta de garantía de ingresos francesa (RMI), señala que

Es cierto que este tipo de contrato [el contrato de inserción como proyecto] es a menudo ficticio porque el demandante se encuentra difícilmente a la altura de tal exigencia. Pero es entonces el trabajador social el que juzga la legitimidad del contrato [...] Este último ejerce así una verdadera magistratura moral (ya que se trata en último término de apreciar si el demandante «merece» el RMI), muy diferente de la atribución de una prestación a un colectivo con derechos, ciertamente anónimos, pero al menos que aseguran la automaticidad de la distribución (Castel, 1999, p.763) ${ }^{6}$

Partiendo de aquí podemos entender que la orden de participación penetra cada vez más profundamente en la personalidad de los beneficiarios a quienes es demandada una implicación cada vez más personal (Béguin y Bertrand, 2012). El proyecto, la implicación personal, la responsabilización en la gestión del propio proyecto vital puede a veces aparecer como un nuevo criterio de mérito. Pero no todos los proyectos son considerados como legítimos o simplemente viables. La inserción social es asimismo modelada por las instituciones, que simplemente desconocen o descalifican algunas veces ciertos vínculos.

\section{Trabajo Social en el contexto de crisis}

La nueva gramática social nos hace volver la vista hacia el papel del Trabajo Social. Porque en un contexto en el que la precarización se instituye como gobernanza y como forma de subjetivación, el Trabajo Social — sus formas y definiciones - nos permite entender una buena parte de la puesta en práctica de esta gramática social.

Partimos de una concepción de Trabajo Social como intervención fundada. Esto significa que el Trabajo Social tiene una naturaleza, pero no en un sentido metafísico, sino histórico-social, lo cual implica que está condicionada por las coordenadas de tiempo y espacio que van resignificando sus elementos constitutivos. Esto conlleva que si los condicionantes socio-históricos cambian, correlativamente lo hará la naturaleza socialmente condicionada del Trabajo Social. Así, si la consolidación de la profesión del Trabajo Social se corresponde con la consolidación del Estado de bienestar - momento en que lo social se vincula al reconocimiento de derechos sociales, a la inversión en políticas sociales y al avance en la acción social pública, con el consecuente declive de la asistencia social privada basada en el voluntariado, propia de una concepción pre-moderna-, la deconstrucción del Estado de bienestar asociada a la crisis configura unas nuevas coordenadas de ubicación del Trabajo Social. Ahora bien, este proceso de ajuste lejos de ser automático va a exigir alguna forma de reflexión y autoconceptualización por parte del propio trabajo social, o mejor aún, por parte del trabajador/a social en situación.

Porque la nueva configuración social coloca en el centro de la escena la tensión que ha acompañado desde sus orígenes al Trabajo Social. Nos referimos a la tensión que contrapone la lógica de la acción social, emancipadora y transformadora, a la lógica más tradicional de la asistencia. Es sin duda esta doble referencia la que va a alimentar todas las figuras paradójicas que encuentran los trabajadores sociales en lo cotidiano y que periódicamente crean crisis (Julier, 2004). La nueva concepción de lo social coloca bajo el foco esa tensión obligando al trabajador/a social a tomar posiciones de un lado u otro. La diferencia está ahora en el locus de la resolución de esa tensión, pues de ser una tensión intrínseca a la definición del trabajo social y su naturaleza que se resolvía en numerosas ocasiones combinando ambas posiciones, pasa a ser una condición estructural extrínseca que obliga a ca-

\footnotetext{
6 Traducción de las autoras.
} 
da sujeto a posicionarse individualmente en su ejercicio profesional, lo cual nos puede permitir hablar de tipologías en función del posicionamiento en situación de cada sujeto.

Volveremos más tarde sobre este punto. Ahora nos interesa detenernos en describir los rasgos de la nueva configuración social que están marcando la naturaleza socialmente condicionada del Trabajo Social.

En el contexto de crisis, y bajo la égida de políticas neoliberales, los problemas y procesos sociales se naturalizan de tal modo que aparecen dibujados como fenómenos inevitables de la realidad (Ávila y Malo de Molina, 2010). En esta misma medida, a las políticas públicas no les compete corregir estas dinámicas, sino generar dispositivos capaces de posibilitar la autorregulación de lo social. Los mecanismos de intervención se reducen a evitar situaciones de riesgo que impidan el buen funcionamiento autónomo, autorregulado, de lo social. Esta definición de la realidad exige al trabajador/a social que entienda su intervención, desde una posición formalista y reglamentista, como regulación de mínimos conforme a los requisitos establecidos. Así, si los fenómenos son naturales, siguen su propio curso de acción, el/la trabajador/a social tendrá que analizar cada caso en sí mismo para apreciar, evaluar, juzgar situaciones desde su ajuste (justesse) a la norma (Soulet, 2014). En este planteamiento la tensión entre lógica de la acción social y lógica de la asistencia se resuelve, institucionalmente, del lado de la segunda pues, desde el punto de vista del mandato, desaparece la posibilidad de hacer confluir la lógica de la asistencia con la lógica de la acción social ${ }^{7}$.

Por otro lado, desde la naturalización de los problemas sociales se entiende que la institución tiene que ser lo más flexible posible a la hora de intervenir, de tal modo que la planificación a medio y largo plazo se sustituye por un procedimiento de ensayo y error ubicado sobre el terreno, abierto a los cambios coyunturales, y sometido a técnicas racionalizadoras de la gestión. En tanto en cuanto lo social deja de ser sujeto, para ser objeto de gobierno, los daños colaterales de la gestión flexible se vuelven secundarios; carece de importancia destruir, en el proceso, los sueños, esfuerzos, expectativas, redes de confianza de un puñado de personas trabajadoras y de otras tantas usuarias (Ávila y Malo de Molina, 2010). Al fin y al cabo, las instituciones sociales son empresas como las demás regidas por criterios de eficacia y de rentabilidad. La única diferencia es que su mercancía, el producto con el que trabajan, es social (Julier, 2004).

Bajo el predominio de las técnicas racionalizadoras, en el tiempo de la ingeniería y del marketing social en el que el ser humano deviene un número de seguridad social, un problema a resolver, una situación a gestionar, la prestación social se cuenta en minutos y la intervención en gestos o en comportamientos a respetar, según Julier, el Trabajo Social se transforma porque los y las trabajadoras sociales se encuentran obligados a responder a las exigencias organizacionales y de gestión - consideraciones administrativas, reglamentos cada vez más precisos, fichas que cumplimentar, procedimientos a respetar, etc.- que se sitúan por encima de la relación humana. Como afirma Julier, invitado el Trabajo Social a considerarse como una empresa parecida a otras, es conminado a vender su imagen en términos de competencia y eficacia. Sin embargo, «la realidad es que nadie tiene ganas de escuchar lo que lo social puede vender: la miseria, el sufrimiento y el fracaso» (Autès, 2013, p.139), de modo que la competencia y la eficacia acaban reduciéndose a eficiencia cuantitativa (tasas de éxito, relación costes-beneficios, etc.) como criterio de justificación de la intervención (Soulet, 2014).

Inmersos en este proceso de justificación-legitimación, los y las trabajadoras sociales se enfrentan a una contradicción que supera y reubica la vieja tensión entre lógica de la acción social y lógica asistencial. La justificación en términos de eficiencia obliga a movilizar simultáneamente dos principios heterónomos de eficacia relacionados con dos categorías de actores: los usuarios, por un lado, y los mandatarios por otro (ídem). Por un lado, el/la trabajador/a social de-

${ }^{7}$ Según Julier, «el/la trabajador/a social conoce las contradicciones y los límites de su acción: apoyar a los individuos al mismo tiempo que promover acciones colectivas y comunitarias; buscar un apartamento para una familia que está en la calle, intentando movilizarla y realizando acciones para denunciar la política en materia de vivienda; proteger a un/a menor de un contexto familiar violento, denunciando al mismo tiempo las causas socioeconómicas de estas situaciones» (2004, p. 9). 
be dar cuenta de su acción a sus mandatarios institucionales y, más concretamente, a los decisores administrativos y políticos. Tiene que objetivarla para que se pueda evaluar su efectividad y eficacia. Por otro lado, debe obtener el consentimiento, la legitimación de las personas usuarias. Para conciliar estos dos contrarios está obligado/a a un doble juego y a mostrar facetas diferentes de su actividad según las personas con las que interactúa. En efecto, poco tienen en común lo que dice en el coloquio singular con la persona usuaria y lo que se lee en el informe oficial transmitido a las autoridades (ídem).

Las prácticas de ajuste y justificación terminan por delimitar una definición del sujeto con el que, en su tarea profesional, interactúan él/la trabajadora social. En el fondo no es sino una redefinición de la demanda. En el momento de bonanza económica y desarrollo del Estado de bienestar, el sujeto se constituye a partir de la idea de sujeto de derechos, destinatario, en última instancia, de reparación de la injusticia social. En esta línea, una demanda de intervención no era sólo una solicitud individual basada en una necesidad individual. Era una demanda social insatisfecha que debía ser cubierta por el Estado (Garello y Ponzone, 2013). En esa medida, el Trabajo Social cumplía un rol ineludible en la mediación, un rol clave en la articulación de la relación persona usuaria-institución ya que su tarea consistía en buena medida en diagnosticar. Esto le permitía al trabajador/a social conciliar asistencia y acción social desde la lógica de la emancipación, del cambio social, de la realización del principio de justicia mientras satisfacía exigencias provenientes del mandato institucional en el que se insertaba. La siguiente cita de Autès refleja bien este papel mediador:

El trabajador social se quiere y se piensa mediador. Es la autodefinición que se encuentra la mayoría de las veces en todos los puntos del campo. Pero lo imposible e insostenible de esta posición hace que se mantenga siempre en la incertidumbre de no poder alcanzar hasta el fin su gesto. No puede tomar completamente el partido de las personas marginalizadas por el funcionamiento de la máquina social, a riesgo de parecer irresponsa- ble y de desacreditarse. Y no puede tampoco colocarse completamente del lado de los mandatarios de la sociedad que demandan su acción, a riesgo de convertir ésta en ineficaz hacia quienes son sus públicos. Es obligado entonces a oscilar sin cesar entre las dos posiciones [...] Es por ello que tomar al pie de la letra a los emancipadores del trabajo social, como a los que lo estigmatizan como una empresa de control social bajo la apariencia de servicio de recursos, es faltar al hecho de que estos enunciados forman un todo, necesario para el funcionamiento social (Autès, 2013, p. 75) ${ }^{8}$.

La naturalización de los problemas sociales y la aplicación de técnicas racionalizadoras de gestión modifican esta situación. La persona usuaria sujeto de derechos se convierte en beneficiaria y/o cliente. La figura de la persona beneficiaria se entiende a partir de la transformación de la demanda social insatisfecha en necesidad básica insatisfecha, en condiciones de crisis y precarización. El sujeto destinatario de la acción se define a partir de ciertos umbrales de ingresos, pobreza y acceso a bienes y servicios básicos. La tarea del Trabajo Social, en la definición política e institucional, consistiría en evaluar, juzgar, definir y ponderar las condiciones de cada individuo en relación a esos baremos. La consecuencia es un sujeto pasivo, carente, sujeto por defecto que se limita a recibir aquellos recursos que el Estado todavía reserva para él mientras se le culpabiliza por no haber sido capaz de responsabilizarse de sí mismo (Garello y Polzone, 2013 $)^{9}$. La noción de cliente deviene de la mercantilización de la relación y de la política social concebida como empresa privatizada. La tarea del Trabajo Social consistiría en atender a la gestión racionalizada de las necesidades y problemas sociales en su expresión privada e individual.

Esta transformación de la conceptualización del sujeto tiene algunas consecuencias que van más allá del simple cambio nominal. Según Soulet (2014), los grandes principios referenciales (derechos humanos, justicia social, decencia, reconocimiento, preocupación por el otro...) no son eficientes para el Trabajo Social en un con-

${ }^{8}$ Traducción de las autoras.

9 Las políticas neoliberales encuentran una coartada perfecta para esta resignificación de la subjetividad en la emergencia de los llamados «nuevos pobres», una clase media crecientemente pauperizada cuya existencia abre el debate en torno a las definiciones de exclusión, marginalidad, vulnerabilidad (Garello y Ponzone, 2013, p. 66). 
texto de incertidumbre estructural en el que los trabajadores y trabajadoras sociales no pueden saber nunca si lo que hacen es justo. Es más, saben que cualquier cosa que hagan no puede hacer justicia teniendo en cuenta las paradojas y contradicciones a las que deben enfrentarse en el ejercicio práctico del mandato (Soulet, 2014). Se enfrentan así a la tarea continua de autoconceptualización profesional con el fin de hacer de su intervención un trabajo ajustado, justo y justificable.

\section{Hacia una tipología de figuras profesiona- les del Trabajo Social}

A partir de los procesos y lógicas de acción descritos en el apartado precedente, y siguiendo a autores como Dubet (1994) y Gaspar (2013), planteamos aquí una posible tipología de figuras profesionales del Trabajo Social cuyas prácticas diferirían en la respuesta a las necesidades y problemas de la ciudadanía en momentos de crisis.

En primer lugar, en correspondencia con la lógica de la asistencia (control), y la de integración que Dubet define como aquella lógica de acción en virtud de la cual «el actor se define por sus pertenencias, que trata de mantener o reforzar en el seno de una sociedad considerada como un sistema de integración» (p. 111), hablaríamos del/la trabajador/a social «normativo/a». Coincidiría, de alguna manera, con la descripción que Gaspar hace de este tipo de trabajador/a social. Para este autor, los trabajadores y trabajadoras sociales normativas tienen una concepción particularmente legitimista de su actividad. Desde su punto de vista ejercen una profesión como cualquier otra, en la que deben aplicar con discernimiento una reglamentación sobre la que, en todo caso, no se pronuncian. Sin ser necesariamente formalistas, atienden a los procedimientos, al respeto de la ley, a las reglas percibidas como factor de integración. Sometiéndose al principio de realidad, controlan, se proponen educar en las reglas del derecho y en las prácticas sociales juzgadas normales. Considerándose personas pragmáticas, se distancian de enunciados teóricos y de los grandes principios ideológicos. Predican únicamente con la práctica, describen situaciones vividas y enuncian soluciones prácticas a las cuales han recurrido en el pasado.

En segundo lugar, coincidiendo con la lógica de la gestión, y con la de la estrategia en la que el actor, según Dubet, intenta realizar la concepción que se hace de sus intereses en una sociedad concebida como un mercado, situaríamos la figura del trabajador/a «gestor/a» que busca la eficacia cuantitativa y se rige por resultados, ajustes entre costes y beneficios, tasas de éxito, etc.

Por último, en correspondencia con la lógica de la acción social (emancipación o cambio social), y la lógica de la subjetivación definida por Dubet como aquella «en la que el sujeto se representa como un sujeto crítico confrontado a una sociedad definida como un sistema de producción y de dominación» (p. 111) encontramos la figura del/la trabajador/a social «crítico/a», «comprometido/a», o, en palabras de Gaspar, del/la trabajador/a social «militante». Los y las trabajadoras sociales críticas consideran que es importante politizar los problemas individuales que presentan las personas usuarias de los servicios sociales. Son particularmente críticos con las políticas públicas y asumen un compromiso al servicio de las personas en situación o riesgo de exclusión (Gaspar, 2013). En este sentido, señala Ariño:

Es preciso cuestionar «nuestro lugar» de control del orden social en ámbitos que despersonalizan y recuperar posiciones en las relaciones de tú a tú, interpersonales; recuperar la confianza en la participación de los otros en la gestión de los programas y de sus propios riesgos, aquellos que afectan a sus propias vidas. Recuperar las significaciones comunes, multiplicar las redes [...] Todo conlleva una determinada opción que, hasta el momento, también denominamos crítica. Una opción decantada hacia las esferas al margen del poder y acompañada siempre por un cuestionamiento de cualquier tipo de cánones o patrones de normalidad (1996, pp. 56-57).

En el contexto actual de crisis la incertidumbre estructural define la gramática social y la forma de subjetivación de los individuos, pero también la naturaleza del Trabajo Social. En su práctica cotidiana, trabajadores y trabajadoras sociales se enfrentan a la necesidad de reflexionar, en cada situación, sobre alguna de estas figuras profesionales, o sobre alguna suerte de combinación entre ellas. Y los nuevos retos están precisamente en la forma de resolver esa autoconceptualización.

Lo interesante de esta tipología, por lo tanto, no es la definición que contiene en sí misma, si- 
no la forma que tienen de concebir la relación estructural de la trabajadora o trabajador con lo social-institucional, por un lado, y la relación situacional con el sujeto-objeto de su intervención, por el otro. Pero sobre todo, la forma en que en cada caso resuelven estas definiciones para justificar y legitimar su propio papel profesional. Esto abre una pregunta de investigación en la línea de resolver cómo la gramática social de la crisis captura y modula la subjetividad de los trabajadores y trabajadoras sociales, porque como señala Autès:
Necesariamente doble, el espacio en el que se despliegan las prácticas del trabajo social está atravesado por un malentendido que no es su falta, su incapacidad para comunicarse, sino un elemento que le caracteriza como práctica social, y el resorte mismo de su eficacia. Esta duplicidad es estructural. Proviene de su relación con su objeto, y de la orden paradójica que lo informa: decir lo que la sociedad no quiere oír, mostrar lo que no puede ver; ser al mismo tiempo el mandatario de las instituciones y el representante de las poblaciones; contener posiciones incompatibles y unir lo que se opone y se rechaza $(2013 \text {, p. } 240)^{10}$.

\section{Referencias bibliográficas}

Ariño, M. (1998). El trabajo social y los servicios sociales. Zerbitzuan - Revista de Servicios Sociales, 33, 51-57.

Autès, M. (2013). Les paradoxes du travail social. Paris: Dunod.

Aquin, N. (2001). Hacia una reconceptualización conservadora en el Trabajo Social. Conciencia Social, 3. Córdoba: Escuela de Trabajo Social de la Universidad Nacional de Córdoba, Argentina.

Ávila Cantos, D. y Malo de Molina, M. (2010,). Manos invisibles. De la lógica neoliberal en lo social. III Jornadas Políticas migratorias, justicia y ciudadanía, Madrid, 27-29 de octubre.

Barrera, E., Malagón, J. L. y Sarasola, J. L. (2013). La deconstrucción del Estado de bienestar: cambios en el ejercicio profesional de los trabajadores sociales y aumento del voluntariado social. Cuadernos de Trabajo Social, 26(1), 115-126.

Beck, U. (1998). La sociedad del riesgo. Hacia una nueva modernidad. Barcelona: Paidós.

Béguin, H. y Bertrand, L. (2012). Une approche critique de l'individualisation des politiques sociales: pistes de réflexion. En B. Muller, J.-Cl. Barbier y M. Bresson (dirs.), Les solidarités à l'épreuve des crises (pp. 95-112). Paris: L'Harmattan.

Butler, J. (2009). Frames of War. When is Life Grievable? Londres: Verso.

Cáritas (2013). VIII Informe del Observatorio de la Realidad Social. Equipo de Estudios Cáritas Española. Recuperado de http://edit.um.es/exclusionsocial/files/2014/02/2013-C\%C3\%A1ritas.pdf (Consultado el 16 de febrero de 2015).

Castel, R. (1999). Les métamorphoses de la question sociale. Paris: Gallimmard.

Colectivo IOE (2013). Expansión del neoliberalismo y políticas sociales. Una lectura de la crisis desde el Barómetro Social de España. Recuperado de Consultado el http://barometrosocial.es/archivos/BSE2011_PolSoc.pdf (Consultado el 16 de febrero de 2015).

Dubet, F. (1994). Sociologie de l'experience. Paris: Seuil.

Garello, S. y Ponzone, J. (2013). Los sujetos de la intervención en el proceso metodológico. En A. Arias, E. Zunino y S. Garello (comps.), El proceso metodológico y los modelos de intervención profesional. La impronta de su direccionalidad instrumental y su revisión conceptual actual. Buenos Aires: Departamento de Publicaciones de la Facultad de Derecho y Ciencias Sociales de la Universidad de Buenos Aires.

Gaspar, J.-F. (2012). Tenir! Les raisons d'être des travailleurs sociaux. Paris: La Découverte.

INE (2014). Encuesta de Condiciones de Vida (ECV), Madrid: INE.

Julier, C. R. (2004). Travail social en crisis, travail social de crisis. En O. Amiguet y C. R. Julier (eds.), Les enjeux contradictoires dans le travail social. Perspectives systémiques (pp. 7-1). Ramonville Saint-Agne: Éditions érès.

Lorey, I. (2011). Governmental Precarization. Tranversal, European Institute for Progressive Cultural Policies, 1, pp. 1-11. [On line]. Recuperado de http://eipcp.net/transversal/0811/lorey/en (Consultado el 16 de febrero de 2015).

\footnotetext{
10 Traducción de las autoras.
} 
Netto, J. P. (2002). Reflexiones en torno a la «cuestión social». En VV.AA. Nuevos escenarios y práctica profesional. Una mirada crítica desde el Trabajo Social. Buenos Aires: Espacio.

Sassen, S. (2010). A Savage Sorting of Winners and Losers: Contemporary Versions of Primitive Accumulation, Globalizations, 7(1-2), 23-50.

Soulet, M.-H. (2005). Une solidarité de responsabilisation. En J. Ion (dir), Le travail social en débat $[s]$ (pp. 86-103). Paris: La Découverte.

Soulet, M.-H. (2014). Par-delà les príncipes normatifs surplombants, des enjeux professionnels de justesse. Journée nationale de Bienne, 19 marzo.

Zurdo Alaguero, A. y Serrano Pascual, A. (2013). Los «nuevos pobres»: representaciones colectivas sobre la crisis y la pobreza en las nuevas capas sociales vulnerabilizadas. En REPS, Las politicas sociales entre crisis y post-crisis. IV Congreso Red de Estudios sobre Políticas Sociales. 6-7 de junio. 